\title{
The wide-angle reflection eye camera for visual choice and pupil size
}

NORMAN H. MACKWORTH HARVARD UNIVERSITY ${ }^{1}$

A new equipment has been devised to photograph the reflection of the stimulus scene in the eye. The resulting motion pictures show the pupil encircling the area of the scene which was being fixated by the gaze; they also show the pupil size. Both measurements are simplified by providing a calibrated edge to the scene. No bite bar is required, and the equipment is quick and easy to use, being especially suitable for young children and also for monkeys.

New procedures are needed to measure the intelligent use of eye movements during tasks involving thinking (Mackworth, 1967). The viewer visually selects those areas of the scene which he thinks will give him the information he requires. Even during the casual inspection of pictures to establish a preference, many selective visual choices are being made (Mackworth \& Morandi, 1967). Most of the fixations fall on the unusual and informative details and unpredictable contours within such scenes. Ss may also map out future events by their eye movements. Tikhomirov and Poznyanskaya (1966) have recently recorded eye fixations during much harder decisions about the best move to make in a chess problem. A chess master visually examined only the most probable moves by his opponents, thereby revealing many changes in his mental programs, while he was considering his own moves.

Mental activity may also be accompanied by pupil enlargement (Hess \& Polt, 1964; Kahnemann, Beatty, \& Pollack, 1967). It is therefore desirable to make simultaneous line-of-sight and pupll measurements, by photographing the eye with the stimulus scene reflected in it. The area of the scene which lies over the center of the pupil is the area which the $\mathrm{S}$ is directly fixating. The general position of the gaze within the scene is immediately evident.

Still photographs of the reflection of a test pattern in the eye have been used since 1909, in order to examine the roundness of the corneal curvature (Helmholtz, 1962). Line-of-sight studies of visual choice began with the experimenter watching the eyes without making any photographic record (Staples, 1932). Recording the eye by motion pictures (Ling, 1942; Fitts, Jones, \& Milton, 1949) was followed by recording the reflection of the scene in the eye to indicate visual choice (Fantz, 1965; Zinchenko, 1963; Hershenson, 1964; Cowey, 1963; Cowey \& Weiskrantz, 1963; Berkson \& Fitzgerald, 1963). These methods have often contained one or other of three drawbacks now removed by the present method: (1) photographic records were usually made through a hole in the center of the display, with the result that Ss tended to look at the edges of this gap rather than at the surrounding display; (2) very high lighting intensities, up to $5000 \mathrm{ft}-\mathrm{L}$, were used, which would glare like snow in sunlight; (3) it was difficult (or sometimes even impossible) to get a numerical reading in terms of a grid reference of the location of the gaze on the stimulus scene.

\section{Advantages of the Reflection Eye Camera}

(1) The reflection eye camera is easy to operate. This feature should be particularly useful in work with patients, such as schizophrenics (Silverman et al, 1967), or with cases of brain damage (Luria, Karpov, \& Yarbus, 1966). This advantage is also important with children. An earlier version of the reflection camera was used by Vurpillot (1966) to compare the sampling strategies of 68 children at various ages from four to eight. Up to 20 children a day were tested by taking the equipment to the school.

(2) The absence of a bite bar is appreciated by $E$ and Ss alike. This feature is particularly important when the Ss are small children less than six years old or animals such as monkeys. Removal of the bite bar also allows the Ss to speak while they are looking. This is useful when recording immediate introspections, and also in psycholinguistic studies similar to those by Mehler, Bever, and Carey (1967), especially as the changing eyevoice span can now be measured when Ss are reading aloud.

(3) A simple device is adequate because the recording does not have to be highly precise in this kind of testing for visual choice.

(4) The location of the eye fixations on the stimulus scene is quantified by an $x-y$ grid which is an integral part of the stimulus scene, although quite unobtrusive.

(5) The position of the S's hand relative to the scene can also be recorded by the reflection camera, to relate visual and manual choices.

(6) The stimulus scene can be either photographic transparencies or real objects, such as faces, dials, test materials, and response levers.

(7) The viewing distance is variable over a wide range of settings. The shortest distance of 8 in. brings the stimulus object within reach of a small child. The middle distance of 15 in. provides the usual reading distance for adults. The display can be moved as much as $14 \mathrm{ft}$ away from $\mathrm{S}$ to permit 

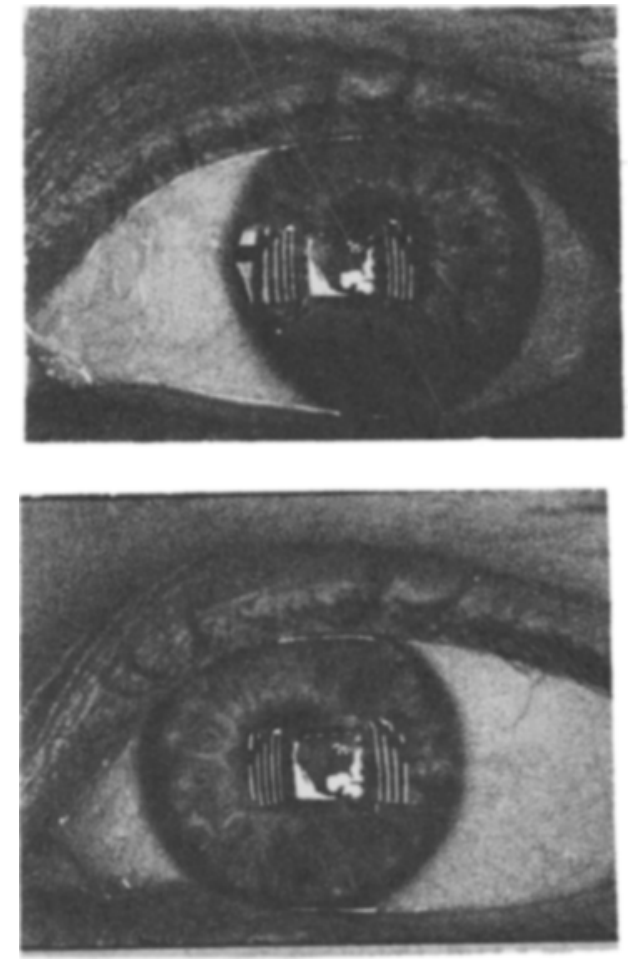

Fig. 1. The pupil center marks the position of the gaze, which moved from East Coast to West. The dotted line around the map gives the exact $x$-y coordinates for this shift. Pupil size is read from the white side lines.

the use of large stimulus panels $10 \mathrm{ft}$ across.

(8) The changing pupil size can be measured simultaneously with the change in the position of the gaze.

\section{Equipment}

Figure 1 shows a pair of unretouched motion pictures which have recorded a large shift in the line of sight completely across a map of the United States from East coast to West coast, so that the center of the pupil moved across the map to encircle California.

These photographs were taken with the new reflection eye camera. This device avoids a hole in the stimulus scene by employing a large half-silvered mirror. As shown in Fig. 2, $\mathrm{S}$ sees the stimulus scene by looking horizontally through this transparent surface. The recording camera photographs the eye from the image reflected off the upper surface of this same mirror. $S$ is not aware of the presence of the camera. All he can see is the bright stimulus picture without any break in its surface.

The glare problem has been solved mainly by brightening the scene. The simplest way to do this is to use a large color transparency, strongly lit from behind. $S$ tolerates more light on his eye when the light comes from the scene that he is inspecting. Figure 2 shows the pathway whereby photographs can be taken of the image of the stimulus: (1) The light from the stimulus travels horizontally through the transparent mirror to reach the eye. (2) The image of the eye with the reflected map travels horizontally back in the reverse direction, to return to the slanting transparent mirror. (3) This mirror now reflects the image upward into the downward facing lens of the movie camera.

Real objects can also be used for the stimulus field, just as Ansel Adams (1956) did when he photographed a brightly-lit violinist reflected in the eyeglasses of the listener. The balance between the stimulus scene lighting and the eye lighting is most important. Extra light has to fall on the eye so that the edges of the pupil are lit just as much by this as they are by the illumination of the stimulus scene. This extra light does not, however, trouble $S$, for the following reasons: (1) The light passes through an orange-red filter. (2) The luminance of the combined light is only $20 \mathrm{ft}-\mathrm{L}$ when reflected off a standard midgray card. This luminance is about the same as foliage in shade. (3) An area source rather than a point source is used, and this is placed as peripherally as possible, $50 \mathrm{deg}$ to the right of the line ahead. (4) Although the light appears to be continuous, in fact it comes from an electronic tube flashing at 60 flashes per second. (5) Each frame is exposed for $1 / 12 \mathrm{sec}$, during which it receives five flashes. Because each flash lasts for only 1 msec, the eye tremors do not blur the pictures. Figure 1 was taken by a $16 \mathrm{~mm}$ motion picture recording at 5 frames/sec, with a $100 \mathrm{~mm} \mathrm{f} / 4.5$ lens, the Kodak Tri-X negative film later being developed in Acufine.

To obtain quantitative digital data in the form of $x-y$ grid readings, the display is visually enclosed in a Harvard square, which consists of a slotted frame (see Fig. 1). There are 10 steps on each side, alternately black and white. The recorded

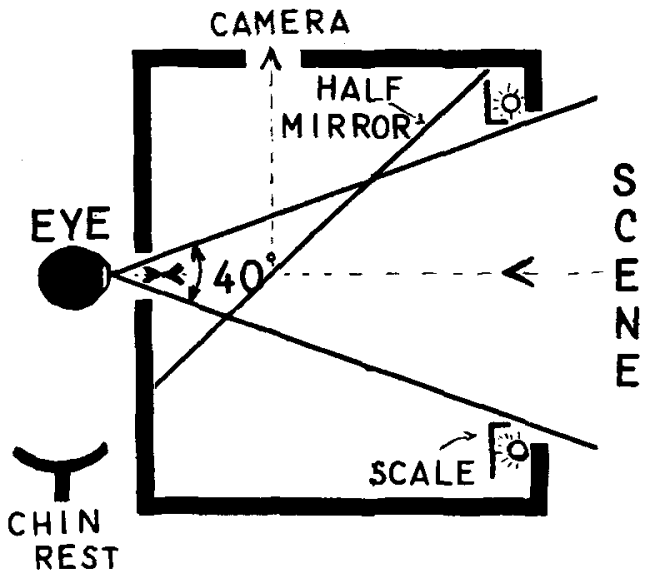

Fig, 2, Diagram of Wide-Angle Reflection Eye-Camera (side view). 
$16 \mathrm{~mm}$ film strip is back-projected onto a light table, one frame at a time. By means of a crosswire in a Plexiglas cursor, the experimenter can determine the $x-y$ grid reference by row and column for each eye fixation on the scene. Each twofigure grid reference is typed on the key board of a Flexowriter as soon as it is read off the record -so that subsequent computer analysis can undertake the calculation and tabulation of the data. Nine-tenths of the time required for hand analysis is devoted to calculation; only one-tenth is spent on the actual reading of the grid references. Therefore automation of the reading of the grid references is not so important.

When the stimulus display is $8 \mathrm{in}$. square and 15 in. distant, the gaze is within $0.5 \mathrm{in}$. of its indicated position. In order to maintain this level of accuracy with a larger display, such as $10 \times 10 \mathrm{in}$. at the same viewing distance, the markings at the corners of the Harvard square have been elongated from 1 in. to 1.5 in. (not shown in Fig. 1). The Harvard square is part of the equipment and is always visible in the eye records, even when the stimulus display itself is a real object or is lacking in contrast, as may occur when $35 \mathrm{~mm}$ slides are presented on a back-projection screen. The slotted mask which provides the Harvard square can be changed if the investigator needs a different grid; this might be a 6 by 6 matrix, when $S$ is choosing between 36 small pictures all simultaneously on view.

The pupil size can also be read from the photograph by the use of a Plexiglas scale. Each of the markings of the Harvard square is usually $0.2 \mathrm{~mm}$ wide on the pupil. Experience shows that the diameter of the pupil can usually be read to the nearest $0.1 \mathrm{~mm}$, and this should be sufficient for the 0.25-0.5 $\mathrm{mm}$ changes which are usually found with information processing. Again, this reading is immediately typed on the Flexowriter for computer analysis.

The vertical parallel lines at the edges of the scene are useful for focusing the movie camera precisely, by ensuring that these lines remain sharp when seen in the through-the-lens view finder. Reflected objects show an enormous depth of field, everything from $7 \mathrm{in}$. to at least $15 \mathrm{ft}$ being sharply defined, once the camera is focused on these side lines.

Convenience of operation is ensured by further aiming devices to permit quick and easy tracking of the eye so that it remains in the field of view of the camera despite sideways or vertical movements of the head. A simple head rest and chin support help to keep the right eye in the middle of the stimulus picture. Cowey (1963) has shown that variations of $0.5 \mathrm{in}$. in head position do not impair the accuracy of a reflection system of this sort. One last indication that the device is indeed easy to use is that the investigator can start taking his records within 5-10 sec after $S$ arrives at the equipment.

\section{References}

Adams, A. The negative: Exposure and development. Hastings on Hudson, N. Y.: Morgan and Morgan, Inc., 1959.

Berkson, G., \& Fitzgerald, F. L. Eye fixation aspect of attention to visual stimulation in infant chimpanzees. Science, 1963, $139,586-587$

Cowey, A. The basis of a method of perimetry with monkeys. Quart. J. exp. Psychol., 1963, 15, 81-90. (35 refs.)

Cowey, A, \& Weiskrantz, L. A perimetric study of visual field defects in monkeys. Quart. J. exp. Psychol., 1963, 15, 91-115. (61 refs.)

Fantz, R. L. Behavior of non-human primates, Vol. II, New York: Academic Press, 1965. Chap. 10.

Fitts, P. M., Jones, R. E., \& Milton, J. L. Eye movements of aircraft pilots during instrument-landing approaches. Aero. Engng. Rev., 1950, 9, 1-16.

Helmholtz, H. V. Treatise on physiological optics, Vol. I. Translated from 3rd German Edition. J. P. C. Southall (Ed.), New York: Dover, 1962.

Hershenson, $M$. Visual discrimination in the human newborn. $J$. comp. physiol. Psychol., 1964, 58, 270-276.

Hess, E., \& Polt, J. Pupil size in relation to mental activity during simple problem-solving. Science, 1964, 140, 1190-1192.

Kahneman, D., Beatty, J., \& Pollack, I. Perceptual deficit during a mental task. Science, 1967, 157, 218-219.

Ling, B. C. A genetic study of sustained visual fixation and associated behavior in the human infant from birth to six months. J. genet. Psychol., 1942, 61, 227-277.

Luria, A. R., Karpov, A., \& Yarbus, A. L. Disturbances of active visual perception with lesions of the frontal lobes. Cortex. $1966,2,202-212$.

Mackworth, N. H. A stand camera for line-of-sight recording. Percept. \& Psychophys., 1967, 2, 119-127.

Mackworth, N. H., \& Morandi, A. J. The gaze selects informative details within pictures. Percept. \& Psychophys., 1967, 2, 547 552.

Mehler, J., Bever, T. G., \& Carey, P. What we look at when we read. Percept. \& Psychophys., 1967, 2, 213-218.

Silverman, J. et al. Eye movements, scanning behavior and perceptual disorder. Percept. mot. Skills, 1967, (in press).

Staples, R. The responses of infants to color. J.exp. Psychol, $1932,15,119-141$

Teuber, $\mathbf{H}$. L. The frontal granular cortex and behavior. J. M. Warren \& K. Akert (Eds.) New York: McGraw Hill, 1964. Chap. 20.

Tikhomirov, O. K., \& Poznyanskaya, E. D. An investigation of visual search as a means of analyzing heuristics. (Trans). Soviet Psychol., 1966-1967 (Winter), 2, 2-15.

Vurpillot, E. Judging visual similarity: the development of scanning strategies. Harvard University Center for Cognitive Studies, Memorandum, 1966.

Zinchenko, V. P., Van Chzhi-tzin \& Tarakanov, V. V. The formation and development of perceptual activity. (Trans). Soviet Psychol. Psychiat., 1963, 2, 3-12.

\section{Notes}

1. Now at Dept. of Psychiatry, (Neuropsychology), Stanford University School of Medicine, Palo Alto, California, 94304.

2. This research was supported by the National Science Foundation, Contract \#GS-192, and by the Cooperative Research Program of the Office of Education, U. S. Dept. of Health, Education and Welfare, Contract \#OE-4-10-136, Project \#E-020, both to Harvard University, Center for Cognitive Studies, and also by the National Aeronautic and Space Administration Research Grant NsG718, to Harvard University, Guggenheim Center for Aerospace Health and Safety. Discussions with Dr. J. S. Bruner and Dr. G. A. Miller clarified the design needs, and J. Millikan and M. Cowtun gave technical assistance.

(Accepted for publication September 12, 1967.) 